\title{
RHETORICAL ASPECTS OF ECONOMIC
}

\section{ANALYSIS}

\author{
Vasko Vassilev \\ “Todor Kableshkov" University of Transport, Sofia, Bulgaria
}

CMESTE

JEL Category: 011

\begin{abstract}
With the growth of knowledge, the theory is becoming more complicated, which reduces the opportunities for their rational and accessible presentation. Research of the phenomena in the development, it engaged a large number of scientists. There are different positions about nature, principles, and approaches on the rhetoric of economic analysis. But what is the result of its rapid development? - The answer is not unequivocal. Disclosed are the majority of the patterns on the economy. This, unfortunately, does not create sufficient conditions for conflict-free and sustainable development. There are many reasons, but one of them undoubtedly lies in the shortcomings of public speaking at the presentation of economic analysis. The practical implementation of the conclusions of the economic analysis is based on the subjective choice that can be manipulated. This means that not only adjusting the subjective choice, but also the behavior to achieve certain objectives is the purpose of speaking.
\end{abstract}

Keywords: Economics analysis, rhetoric, manipulation, argumentation impact development

\section{INTRODUCTION}

At the beginning of the XXI century, it seems that everything is discovered, analyzed and systematized. It remains only better to understand and apply in practice. Unfortunately, this is not so. With the growth of knowledge is complicated theoretical, and this reduces opportunities for their rational and accessible presentation. Research of the phenomena in the development engaged a large number of scientists. There are different positions about nature, principles, and approaches. But what is the result of rapid

Address of the author:

Vasko Vassilev

䤵"vasko.ananiev@gmail.com development? - The answer is not unequivocal. Disclosed are the majority of the patterns on the economy. This, unfortunately, does not create sufficient conditions for conflict-free and sustainable development. The reasons are many, but one of them undoubtedly lies in the shortcomings of public speaking at the presentation of economic analysis. The practical implementation of the conclusions of the economic analysis is based on the subjective choice that can be manipulated. At the same time established a rule that the specific characteristics of the processes are considered a priori to known and established practice. This undoubtedly is concept error, but along with it is conscious or unconsciously sought compromise outcome. 


\section{RHETORIC AND MANIPULATION}

One means of adjusting the subjective choice, but also the behavior to achieve certain objectives is speaking. This function of rhetoric has accompanied the entire history of mankind. The importance of public speaking increases with changes in social environment. At the same time, the role of the rhetoric is changing with the growth dynamics of the development and complication of social processes.

In recent years we have seen a worse talking about the economy. The reason for this should not be sought only in negativity and incompetence on the part of the speakers, but in discarding the economy, and the rhetoric of the dynamics and needs of society. We need to change attitudes towards the development and application of these sciences in practice.

It is necessary to develop and define new approaches and techniques for the integration of modern economic analysis and rhetoric. Such unity can be achieved by revealing the fundamental processes of economic development and the role and place of rhetoric and speakers in them (Petho, 2005). The foundation of this concept is revealing interdisciplinary connections and dependencies and includes a wide range of knowledge from other sciences in the organization of public speaking. This is especially useful for the formation of a large number of models for the analysis of different objects. And also for the presentation of rhetorical argumentation as a major factor for the integrity of social systems, which are subject to economic analysis. The topicality of the issue of the social importance of argumentation in the modern world is growing as a consequence of the growth of the role of information technology. Information society imposes increasingly clear presentation of arguments on various points, especially in terms of economic development.

The main tasks that need to be addressed can be summarized as follows:

- Analyzing the problems of theories of rhetoric and economic analysis in order to highlight the impact on public awareness through public speaking appearances, the formation of public value systems, as well as particularly topical aspects of rhetorical theory as communicative and its impact on economic development.

- Develop an algorithm to analyze the rhetorical events, which make it possible to study complex arguments and their structure and place in the economy.

- Study of the linguistic means for forming images of economic development in the rhetorical works.

\section{SOCIAL COMMUNICATION AS A TOOL OF ECONOMIC ANALYSIS}

These tasks can be solved by integrating logic analysis with the analysis of discourse in the study of rhetorical arguments for presentation of economic analysis. Public speeches are directed not only towards the creation and preservation of social norms but also to change and update of reality. In this sense, the rhetoric has the function of an organizer of social communication, without which it is impossible economic development. Especially important are communicative aspects in the process of argumentation that should be seen as a form of communication.

In modern language, the word "rhetoric" is often loaded with bad sense. It usually refers to "empty speech" by politicians or traders who want to deceive the voters or customers, using wellrepresented discourse in order to conceal the truth and manipulation.

This is only part of the truth about rhetoric because the way in which researchers present their work is almost as important as the content itself. Argumentation, which is a structural element of the rhetoric is widely used approach for the communication of science, so that they can be understood and others to benefit from them. In this sense, the art of argumentation is essential for the development of knowledge through scientific communication. The rhetoric here can be defined as a motivated way to argue that gives clarity of meaning and arguments. Thus the rhetoric becomes part of scientific inquiry, says McCloskey (McCloskey D. N., 1983) Key features of communication are standard. These are words or tools that are understood and accepted by the community. According to McCloskey (1998): "Even in the most narrow technical issues economists have shared beliefs about what makes a strong argument." This means that the 
scientific community of economists has developed standards for what is a convincing and unconvincing argument. A problem arises when these standards are used to justify insufficiently studied phenomena or to communicate with poorly trained specialists.

For example: In the rhetoric of economists, quantitative methods are the most widely used, i.e. everything is written in numbers, it is clear and true. This perception, however, is often wrong. The problem is that numbers are important just because people give them meaning. Two is a lot or a little, depending on what we're talking about. The brain thinks about it by its relative value. I.e. two, in our case, counts only as something the brain refers to the process of comparison and reference. The question: "How big is big?" No one can answer. Mathematics without the brain that controls the mathematical tools is useless. According to McCloskey, the economy, and in particular econometrics, have made a big mistake they have placed mathematics before rhetoric in importance. Fetishization of mathematics transforms economic rhetoric in the pseudoscientific ceremony. At the core of this transformation stands the replacement of scientific relevance with statistical significance. „It seems that economists want to explain what is happening in a world that can be formalized, not in the real world." (McCloskey D. , 1998)

"The rhetoric is a system of practical tools for impact." In the politics, as professor writes (Aleksandrova, 2012) "Public opinion is influenced by discussions of truth, morality, and justice, but neither their result nor under their control." But discussions about the economy do not lead to the same result. Here the main parts of the economic performance are the result of public opinion formed by public influence and in many cases, through manipulation.

We will analyze the rhetoric of some of the leading economists and politicians in the world. Changes in the economy have rarely been predicted and often were not recognized until they happen. Economists are divided into two groups: those who cannot know the future, but they think they are able and those who recognize the "inability" to do so. In rhetoric, both economists and politicians (speaking of the economy) is a characteristic combination of rhetorical figures between them and combining them with arguments and psychological mechanisms in the communication act. The first models of social communication appear in the rhetoric. Aristotle rhetorical model emphasizes the role of the speaker, who through his speech must convince the audience in the power of their arguments.

In the model of Shannon and Weaver (1949), along with traditional elements in the process of direct communication has introduced a new element - noise. The introduction of noise in the process of communication is linked to the idea of the factors that can modify the message. Noise can be physical (related to the characteristics of the physical environment in which unfolds in communication) or semantic (caused by the action of a variety of psychological obstacles in the process). For the purpose of our study, it is important primarily semantic noise, which is determinative of the outcome of the impact of economic rhetoric.

$\mathrm{N}$. Wiener enriched data model of Shannon and Weaver with a new, extremely valuable component - feedback that indicates how well understood the message. Feedback is an indicator for how the rhetoric supports the process of shaping opinion in the audience and decisionmaking.

In the rhetoric of economists, rhetorical figures are not very widely used. Here dominates informative function of speech implies reduced application of verbal decorations and clear, concise and accurate expression. Attracting and retaining the attention has been achieved through effective use of rhetorical figures before or after the rhetorical arguments.

In contrast to the rhetoric of economists, in political speech, the speaker does not allow communication barriers and misunderstanding of what it says. "The political rhetoric has the opportunity to reconstruct the political reality for members of the audience, based on which they make decisions and act in accordance with them." (Aleksandrova, 2012)

Rhetorical effect on political speech for the economy has not a momentary effect, but the result of planned and prepared communicative strategy. High frequency of use of figures that do not lead to difficulties in attending to decode their 
meanings. Preferred the figures that create the impression of a dialogue with the audience.

\section{ECONOMIC RHETORIC AND SOCIAL DEVELOPMENT}

Unfortunately, is widespread bad practice to offer intuitive models for economic development with the tag "rational". The reasons for this are the result of "rational wave" when mathematical modeling, computerization, and Automation of the process were accompanied by expectations that they will solve "all" problems. Scientists and managers who launched the economy based solely on the qualities of economists and social communication missed several important events:

- Much of the activities (processes) really become more technical and thus rationalized, but partially. These activities are already "scored" in "rational technological frameworks" and economists are now depending on them, whether they recognize it or not.

- Because of the more technical take place partly the use of these revolutionary areas (e.g. information provision) for now does not give the expected results. Understanding this problem is of key importance. The paradox is that this "more technical" rational part, even when it is the reason for conducting higher costs, there is no need be waived and that no longer is possible.

- Later it understood that technological approach cannot be applied to all processes in the economy.

- Directly related to the above problems is to understand the simple fact that in society there are processes that can be strictly formalized technical, mathematical and other means, and those not subject to exactly describe and "technology provision." This does not mean that they cannot define a technological sequence to form models, rules, techniques, principles.

It is high time economic rhetoric to recognize that society is dynamic, evolving system. Its completeness is an integral and not a result of mechanical parts collected. These simple truths already understood by all. It remains to be the basis of the real scientific explanation of phenomena and be part of the essence of economic and rhetorical practice using their ability to influence social development.

- Society is an appropriate functioning system, which requires development issues to be considered by the following items:

- Social development does not take place in some imaginary social space. It always is realized through structural configurations with certain properties and certain mechanisms of influence.

- Society originated as a natural phenomenon but is increasingly subjected to the artificial impact of the person.

- The systemic essence of society presupposes the existence of row. The order is impossible without structures organized so as to ensure the functional essence in the way of social communication. The order also represents clear objectives arising respectively appropriateness of social activities; determine the parameters and the way to achieve their goals through planning, design, construction, regulation, resource provision.

- All the above actions are the essentially subject of rhetoric; the main task is to build a society that is stable, predictable, with a clear orientation and sustainable over time.

- Because of the inevitability of social transformation, rhetoric should support processes are under control and conflict-free transition with minimal losses. The other alternative is confusion, apparent row with ambiguous results, lack of logic and sense unclear orientation

Regardless of the dynamics of social development and the changing environment, the effectiveness of economic rhetoric as an instrument of transformation depends on the stability of society. An important condition for this is to cover unity "all" factors that determine sustainability. The impact is most often based on concrete objectives that are not included in a single system that reflects the integrated features of society. This leads to a variety of criteria divergence in action, rude practicality and subjectivity and lack of unity in solving practical tasks.

From the above, we can conclude that we need serious thought and pre-depth study to proceed with the preparation of arguments in determining the approaches and objectives of social 
development. In other words, they must present arguments to convince the audience, regardless of its heterogeneity. The task is complicated, given also that the arguments used in the economy by them are tendentious and stochastic, and are not necessarily correct and true. For example, "Free trade is good" and "Taxes reduce the production" are statements that many economists dispute. Some economists argue that they are 60\% correct, and some $90 \% \ldots$ The heart of the argument is Enthymeme how economist defends probability of 60 or 90 percent as "true enough".

The purpose of economic rhetoric supporting social development does not just understand the arguments and their improvement. The ability to improve through further development is actually practical freedom. The achievement of this freedom is not easy; the secret is communication in which actors should engage more frequently.

Many of the arguments in the economy are difficult to "takeover". However, there may be good reasons to think that the reasons for an argument are in fact unreliable. Or you could simply think that the speaker is an untrusted because retransmit foreign claims. The effectiveness of the reason or the type of evidence depends on the audience and what it generally is convincing.

The persuasiveness of the argument depends on the parts of ethos (character, personal prestige, and reputation) of the speaker and the expectations of the audience. The first step of the speaker is to create its ethos. Experts build ethos by publishing original research in scientific journals and books, as well as lectures on senior appointments. The next step is to introduce the works of the best economists studying the arguments that they find compelling and on this basis to create their own arguments. The argument should not be based solely on emotion. Clarity is needed to be based both on their own values and interests, as well as the values of others.

Economists use the terms "positive" and "normative" in order to distinguish between "what is" of "what should be." They cannot refuse to accept the world as both positive and normative. There is no such thing as a single point of view, which is... Lack point of view! Usually, one perspective is "I do not like ... Something or someone" and argumentation is built solely on not liking. Positive statements point out the facts, and can, in theory, be checked. One fact can always be checked, and then decide whether to support a statement or not. Such statements are true - in the sense that the facts are consistent with the statement or false - in the sense that it did not support the allegation. Normative statements express value judgments. This is about opinions, which usually cannot be verified.

Normative statements relate to morals and ethics and they are often used or given words and phrases such as "should" and "would be good." We cannot check the facts in order to decide whether the statement is true or not. Decisions on whether to accept a normative statement or not, form the basis of economic policy and often made on the basis of political values.

Discovering the positive and normative reasoning in direction, facilitates and simplifies talking about economics, but that makes it even more important need for a clear separation of these strands in the argument. Normative conditions tend to dominate discussions where people try to imagine what they want. Positive discussions tend to dominate among scientists because they want to understand how the world works, and believes they do not come in finding regulatory issues.

This is just one example, but sufficiently indicative of fragmentation systematic talking about the economy. The social development suggests economics speakers speak in positive statements and conditions and to refrain from apparently legal advice unless you are asked for them. So, economists should think of themselves as therapists of society (by talking about treatment not acquire the feeling of being sick themselves or through their impact not sick other healthy until then). This does not mean that normative discourse should be ignored completely. The systematic approach requires a combination of positive and normative in the economy to ensure sustainable social development.

\section{CONCLUSIONS}

From the above here are the following conclusions:

- Compression of the problems in the late 20th and early 21st century is the result of 
misunderstanding the global nature of the social system. This leads to continuous attempts with fragmented solutions.

- Neoliberalism in economics, argues global solutions based on local arguments, it only leads to further problems. Moreover, results in the creation of new, unknown until now problems that result from the destruction of the welfare state.

- Economic crises are so clean that you can speak of a continuous crisis since 1987, which could not be stopped with "revolutionary" economic transformations in the post-Soviet space, despite the hopes of many apologists of neoliberalism.

- Economic rhetoric, despite the efforts of economists and politicians, fails to present the methods and approaches in a sufficiently convincing manner neither decision-makers nor ordinary citizens. This is confirmed by examples that are given by one of the top economists and leading politicians. Their speeches are "lean" on to argument here include both species diversity of arguments and their substantive characteristics.

- Speaking Economists and politicians are close to each other, and as this process deepens it becomes a sign of hopelessness. This has another consequence: in the modern language, the word rhetoric is often loaded with bad sense. It usually refers to "empty speech" and well-presented discourse is to hide the truth and manipulation.

- The economic performance increasingly is the result of public opinion formed through public action and in many cases, through manipulation.

- Increasingly offer intuitive models for the development of the economy as they put the tag «rational»

- Still not understood that the integrity of the social system is an integral and not a result of mechanical parts collected. The impact is most often based on concrete objectives that are not included in a single system that reflects the integrated features of society. This has serious implications for social development.

- It needs depth study prior to proceeding with the preparation of arguments in determining the approaches and objectives of social development. The task is complicated, given also that the arguments used in the economy by themselves are tendentious and stochastic, and are not necessarily correct and true.

- The probability of the argument depends in part on the speaker's ethos and expectations of the audience, they increasingly difficult to synchronize, because of problems in both countries.

- There is fragmented, unsystematic talking about the economy. The systematic approach requires a combination of positive and normative in the economy to ensure sustainable social development

It is known that nothing remains permanent and unchanging, eternal is the only change. It may be the very dangerous application of theory, which is not consistent and does not reflect the true state of society. And between the state of society and economic development, there is a special kind complex causality. Only adequate analysis and presentation of economic problems can contribute to the accelerated and efficient development of society. But in the course of this development is changing as content analysis and public representation. For this reason, any theory including and the economy has and will have its historical limits within which it adequately reflects its object.

The more the economic analysis is released by its function to explain social systems and increasingly developed function of a factor for the development of society. More often will be forced to "adapt" to changes and ever will be a short historical time of the existence of theory-object of speaking.

All described problems here are classic, but needed new tools to solve them. Economic development and the impact of rhetoric on these processes should lead to a common future based on resolving contradictions, not the future, programmed by some people with a tolerance for "use" of all. 


\section{Works Cited}

Aleksandrova, D. (2012). Tendentsii v politicheskata retorika na bŭlgarskiya prekhod. Retorika $i$ komunikatsii (3).

McCloskey, D. (1998). The Rhetoric of Economics (second edition). Madison: The University of Wisconsin Press.

McCloskey, D. N. (1983). The Rhetoric of Economics. The University of lowa.

Petho, E. (2005). Introduction to rhetorical economics. European Integration Studies, 4(1), 109-114. http://www.matarka.hu/koz/ISSN_1588-6735/GTK_vol_4_no_1_2005_eng/ISSN_15886735_vol_4_no_1_2005_eng_109-114.pdf

Received for publication: $\quad 01.04 .2016$

Revision received: $\quad 30.08 .2016$

Accepted for publication: $\quad 12.12 .2016$

\section{How to cite this article?}

Style - APA Sixth Edition:

Vassilev, V. (2017, Jan 15). Rhetorical aspects of economic analysis. (Z. Cekerevac, Ed.) MEST Journal, 5(1), 143-149. doi:10.12709/mest.05.05.01.17

Style - Chicago Sixteenth Edition:

Vassilev, Vasko. "Rhetorical aspects of economic analysis." Edited by Zoran Cekerevac. MEST Journal (MESTE) 5, no. 1 (Jan 2017): 143-149. doi:10.12709/mest.05.05.01.17

Style - GOST Name Sort:

Vassilev Vasko Rhetorical aspects of economic analysis [Journal] // MEST Journal / ed. Cekerevac Zoran. - Belgrade - Toronto : MESTE, Jan 15, 2017. - 1 : Vol. 5. - pp. 143-149.

Style - Harvard Anglia:

Vassilev, V., 2017. Rhetorical aspects of economic analysis. MEST Journal, 15 Jan, 5(1), pp. 143-149.

Style - ISO 690 Numerical Reference:

Rhetorical aspects of economic analysis. Vassilev, Vasko. [ed.] Zoran Cekerevac. 1, Belgrade Toronto : MESTE, Jan 15, 2017, MEST Journal, Vol. 5, pp. 143-149. 